\title{
Naxçivanda İslam Mədəniyyəti və Gənclərdə Tolerantliğin Inkişaf Etdirilməsi
}

\author{
DOI: $10.26466 /$ opus.385431
}

\section{Sevinc Cabbarova*}

* Dr. AMEA Naxçıvan Bölməsi, Təbii Ehtiyatlar İnstitutu, İqtisadiyyat şöbəsinin müdiri, böyuk elmi işçi, iqtisad üzrə fəlsəfə doktoru

E-Posta: sjabbar@mail.ru

ORCID: 0000-0001-8166-0841

\section{Öz}

Naxçıvan İslam dininin yayımlanmasında gadim zamanlarda mühüm rol oynayıb, bunu müxtวlif dini abidəlarində təsvir olunmuş sübutlardan görmək mümkündür. İslam dininin maddi va qeyrimaddi irsinin formalaşması ilə bağh müxtəlif tədqiqatlar aparılır va müəyəyn olunur ki, Naxçıvan eyni zamanda, tolerant mühiti ila ahata olunan, müsalman ölkalari ila six alaqada olan, multikulturalizm sahasinda darin tacrübasi olan bir diyardır. Hec tasadüfi deyil ki, İslam dayarlarinin dünyada tabliğina böyük töhfəlar verən Naxçıvan şəhəri 2018-ci il üçün "İslam madəniyyatinin paytaxtı" elan olunmasında öz ifadasini tapıb. Bu baxımdan, sağlam va tolerant ganc nasil yetişdirilmasi aktual bir problema çevirilir. Maqalada Naxçıvan ganclarinin inkişafı tahlil olunur, hamçinin İslam hamrayliyi ideyasının muxtar respublikasında həyata keçirilmasi sahasinda görülan işlardən bəhs edilir.

Açar sözlər: islam madəniyyati paytaxtı, islahatlar, Naxçıvan şəhəri, sosial-iqtisadi inkişaf.

OPUS (c) Uluslararası Toplum Araştırmaları Dergisi-International Journal of Society Researches ISSN:2528-9527 E-ISSN : 2528-9535

http://opusjournal.net 


\title{
Islamic Culture in Nakhchivan and Tolerance in Youth
}

\begin{abstract}
Nakhchivan was one of the main centers of Islamic civilization and played an important role in the spreading of Islam and at the same time establishing the Muslim renaissance. All these things have created the basis of the material and intangible heritage of the Islamic religion from the very beginning in Nakhchivan. Nakhchivan also contributed greatly to the formation of a tolerant environment, the establishment of multiculturalism, intercultural and inter-civilizational dialogue, and the promotion of Islamic values throughout the world. The reputation of Azerbaijan in the Islamic world has been expressed in the announcement of Baku and the Nakhchivan city's "capital of Islamic culture" for the year 2018. The decision to hold the IV Islamic Solidarity Games in Baku in 2017 also created favorable conditions for our country to take the next practical steps to strengthen Islamic solidarity. The article analyzes the development of youth in Nakhchivan, as well as the work done in the implementation of the Islamic Solidarity in the autonomous republic.
\end{abstract}

Keywords: capital of Islamic culture, reforms, Nakhchivan city, socio-economic development

OPUS ( $)$ Uluslararası Toplum Araştırmaları Dergisi-International Journal of Society Researches ISSN:2528-9527 E-ISSN : 2528-9535

http://opusjournal.net 


\section{Giriş}

Naxçıvan İslam dininin yayılmasında mühüm rol oynayıb və eyni zamanda sivilizasiyaların beşiyi kimi tanınır. Naxçıvan ərazisində İslam dininin irsinin formalaşması gədim dövrdən başlanmışdır. İllər keçdikdə Naxçıvanda sivilizasiyalararası münasibətlər ərazisi ilə sıx bağlı olmuşdur və bununla da əhali tolerant və multikulturalizm şəkilində inkişaf etmişdir. 2018-ci il üçün Naxçıvan şəhərlərinin "İslam mədəniyyətinin paytaxtı" elan olunması heç təsadüfi deyil, zəngin tarixi və müstəqillik illərində qazanılan sosial-iqtisadi inkişaf bu statusu laiqinçə yerinə yetirməyə hüqüq verir. Bu qərar İslam həmrəyliyinin möhkəmləndirilməsi sahəsində mühüm addımlardan biri kimi qiymətləndirilə bilər.

2009-cu ilin oktyabr ayında Bakı şəhərində İslam Oməkdaşlıq Təşkilatına üzv dövlətlərin VI konfransında Naxçıvan şəhəri 2018-çi il üçün İslam mədəniyyəti paytaxtı elan olunmuşdur. Bu isə Naxçıvan Muxtar Respublikası ərasızındə son illərdə geniş meydan verilən millimənəvi dəyərlərin, əsrlərdən bəri qorunub yaşadılan və yüksək dövlət qayğ1sı ilə əhatə olunan islam dəyərlərinin, islam mədəniyyəti abidələrinin qorunub saxlanması, bərpası, inkişaf etdirilməsi və təbliği sahəsində aparılan işlərin daha yüksək səviyyəyə çatdırılmasında mühüm rol oynayacaqdır. Muxtar Respublikada yaradılan infrastruktur, sabitlik və iqtisadi böhranlara baxmayarad iqtisadi inkişaf regionu tanıtmaq və gələcəkdə turizmi inkişaf etdirmək baxımından böyük əhəmiyyət kəsb edir.

İslam mədəniyyətində xüsusi yer tutan Naxçıvanda yerləşən XII yüzillikdə Әçəmi Obubəkr oğlu Naxçıvani tərəfindən inşa edilən abidələrdə müxtəlif Allaha aid kəlamları, Qurani-Kərimin ayələrindən geniş şəkildə istifadə olunurdu. Naxçıvan şəhərində 1186-cı ildə ucaldılan Möminə xatın türbəsinin tağlarının baş tərəfində Quranikərimdən götürülmüş "Hakimiyyət vahid, qadir Allaha məxsusdur!" ayəsi 10 dəfə təkrar yazılmışdır. Yaxud da Möminə xatın türbəsinində Qurani-Kərimin 83 ayədən ibarət olan "Yasin" sürəsi 2 dəfə təkrar yazılmışdır (Hacıfəxrəddin S. 2017, s. 5). Naxçıvan bölgəsindəki digər memarlıq abidələrinin üzərində yazılan kitabələrdə islam mədəniyyətinə aid Quran ayələrindən yazilar əks olunur. 
Zənqin tarixli keçmişimizə nəzər salsaq, bəşər sivilizasiyasının ən qədim mərkəzlərindən biri olan Naxçıvan şəhərinin Azərbaycanın qədim və orta əsrlər dövrü ictimai-siyasi və mədəni həyatında tutduğu mühüm mövqe və yer çox aydın görunur. Naxçıvan ərazisində son illərdə aparılan tədqiqatlar təsdiq etmişdir ki, adını Dünya tufanı zamanı Nuh peyğəmbərin gəmisinin Ordubad rayonundakı Gəmiqaya ərazisində quruya oturması və nuhçuları burada torpağa çıxmasından götürən Naxçıvan (Nuxçıxan) şəhərinin adı sonralar daha geniş məna kəsb etmiş, böyük bir bölgənin adını bildirmişdir.

Olverişli təbii-coğrafi mövqedə yerləşdiyi üçün Naxçıvan bölqəsi gədim zamanlardan yüksək inkişaf etmiş, orta əsrlərdə mühüm ticarət yolları burdan keçmiş, Naxçıvan isə təxmini beş minillik bundan əvvəl şəhər kimi formalaşmağa başlayıb (Hacıfəxrəddin S. 2017,, s.13). Yüksək səviyyəli mədəniyyət burada müxtlif xalqların yaşamasına səbəb olmuş, və beləliklə mültikulturalizm və tolerantlıq ənənələri qədim dövrlərdən indiyə kimi bizim xalqa xas olan xüsüsiyyət kimi formalaşı.

\section{Gənclərdə Tolerantlığın Inkişaf Edtirilməsi}

Tolerantlıq Azərbaycan xalqının xarakterik cəhətidir. Yüksək tolerantlıq ilk növbədə yüksək mədəniyyətin təzahürüdür. Azərbaycan müstəqilliyini əldə edəndən sonra dövlətin ideologiyasında da əsrlərdən gələn ənənə möhkəmləndirilib. Fərqli mədəniyyət və din sahiblərinin birgə yaşayışının dövlət səviyyəsində rəsmi təsdiqi var və bu Konstitusiyamızda da təsbit olunub (Hüseynov, S. 2012, s.32). Yaradılan mühit onu göstərir ki, Azərbaycan bütün Cənubi Qafqazda tolerantlıq nümunəsidir. Burada fərqli mədəniyyətlərin, dinlərin birgə yaşayışının xüsusi modeli bərqərar olub.

Muassir dünyanın ikişafında əsas tendensiya kimi ölkərərarası inteqrasiya çıxış edir. Sərhədlərin açılması, Naxçıvan Muxtar Respublikasının bir neçə dövlətlə qonşu olması həyatın bütün sahələrində sıx dövlətlərarası münasibətlərin qururmasına zəmin yaradır. Bu inteqrasiya adət ənənələrin muassirləşdirilməsinə, polietnik əlaqələrin qurulmasına, iqtisadi münasibətlərin qurulmasına gətilib çıxarır. 
Bütün bunları nəzərə alaraq gənclərə və gələcək nəsillərə bu qanunauyğunluqları çatdırmaq bütün mədəniyyətlərdə xususi qayğı simvolu kimi çıxış edir.

Daim inkişaf edən cəmiyyətimizdə müxtəlif mədəni qrupların öz individuallı̆̆ını qoruyub saxlamaq hüququna malik olması məsələsi öz yerini tapmasına və Muxtar Respublikasi üçün müassir dinamik həyata uyğunlaşmasına və nəticədə gənclərin xalqların müxtəlifliyini dərk etmək və öyrənməklə iqtisadi baxımından güclü cəmiyyət formalaşdırmaq üçün təbliğat işləri aparılmalıdır.

Naxçıvan Muxtar Respublikasında dövlət proqramlarına əsasən, maddi və iqtisadi resurslardan səmərəli istifadə edərək, iqtisadi inkişaf modeli formaraşdırılmışdır. Müstəqillik dövründə bütün sosial-iqtisadi sahələrdə inkişaf təmin olunmuşdur. 2016-c1 ildə muxtar respublika üzrə 2 milyard 582 milyon manatlıq ümumi daxili məhsul istehsal olunmuşdur ki, bu da 2015-ci illə müqayisədə 0,5 faiz çoxdur. 2016-c1 ildə hər bir nəfərə düşən ümumi daxili məhsulun həcmi 5779,7 manat təşkil etmişdir, bu isə 2015-ci illə müqayisədə 3,6 faiz artmışdır. Ümümi daxili məhsul istehsalının 60 faizə qədərinin real sektorun payına düşməsi dayanı̆̆lı inkişafın təmin olunmasına öz təsirini göstərmişdir. Sənaye sahəsi muxtar respublikada yaradılan ümumi daxili məhsulun tərkibində ilk yeri tutur. Sənaye sahəsində 2016-c1 ildə 942 milyon manat həcmində məhsul istehsal edilmişdir ki, bu da 2015-ci ildəki göstəricini 1,7 faiz üstələmişdir (Azərbaycanda dini və milli tolerantlıq //Azadlıq.2010.- 20 oktyabr.- 13).

Azərbaycan iqtisadiyyatının kompleks şəkilində inkişaf etməsi "Qlobal Rəqabət Qabiliyyəti İndeksi 2013-2014" hesabatında öz əksini tapıb. Beləliklə, bu reytinqa əsasən, Azərbaycan rəqabət qabiliyyəti səviyyəsinə görə 39-cu, MDB-də 1-ci olmuşdur. Artıq Azərbaycan dünyanın "yuxarı orta gəlirli" və "yüksək insan inkişaflı" ölkələr sırasında öz yerini tutub. Dünyada tanınmış reytinq agentlikləri ("Fitch Ratings", "Standart \& Poor's" və "Moody's") Azərbaycanı Qafkazda yüksək investisiya kredit reytinqi ilə taniyır.

Regionlarda tarix və mədəniyyət abidələrinin bərpası və qorunmas1, tarix və mədəniyyət qoruqlarının fəaliyyətinin təkmilləşdirilməsi və inkişafı, qloballaşma şəraitində mədəni çeşidliliyin daha da inkişaf etdi- 
rilməsi, mədəniyyət obyektlərinin əsaslı təmiri və tikintisi üzrə müvafiq tədbirlərin keçirilməsi prioritet istiqamətlər kimi seçilmişdir.

Bu sahədə qəbul olunan Dövlət Proqramları nəzərdə tutulmuş tədbirlərin həyata keçirilməsi sosial-iqtisadi inkişafında vacib mərhələ olmaqla, ölkə regionlarının davamlı inkişafında və əhalinin rifah halının daha da yaxşılaşdırılmasında mühüm rol oynayacaqdır.

Gənclərdə tolerantlı̆̆ın inkişaf etdirilməsi rügionun mühüm hədəflərindən biri hesab olunur (Tahirova, N., 2015, s.6). Muxtar respublikada gənclərə göstərilən diqqət və qayğı sağlam düşüncəli vətəndaş yetiştirilməsinə gətirib çıxardır.

Heç şübhəsiz ki, ölkədə müəyyən bir sferanın inkişafı üçün həmin sahənin qanunla tənzimlənməsi şərtdir. Azərbaycanda gənclər siyasətinin əsas istiqamətləri "Gənclər siyasəti haqqinda" qanunla müəyyənləşdirilib. Qanuna əsasən, gənc nəsil nümayəndələrinin mənəvi-əxlaqi tərbiyəsi, istedadlı gənclərə yardımlar, sağlamlıq və fiziki inkişaf məsələləri, məşğulluğun artırılması, gənc ailələrə və gənclər təşkilatlarına dövlət yardımı kimi işlərin görülməsi prioritet istiqamətlər kimi müəyyən olunmuşdur. (http://www.sherg.az/2011/12/08 /read=44284, s.76).

Tolerantlıq Azərbaycan xalqının xarakterik cəhətidir. Yüksək tolerantlıq ilk növbədə yüksək mədəniyyətin təzahürüdür. Azərbaycan müstəqilliyini əldə edəndən sonra dövlətin ideologiyasında da əsrlərdən gələn ənənə möhkəmləndirilib.Fərqli mədəniyyət və din sahiblərinin birgə yaşayışının dövlət səviyyəsində rəsmi təsdiqi var və bu Konstitusiyamızda da təsbit olunub. Yaradılan mühit onu göstərir ki, Azərbaycan bütün Cənubi Qafqazda tolerantlıq nümunəsidir. Burada fərqli mədəniyyətlərin, dinlərin birgə yaşayışının xüsusi modeli bərqərar olub. Dini dözümlülüyü, tolerantlı̆̆1 daima dəstəkləyən Heydər Oliyev gənclərimizin bu ruhda tərbiyə olunmasını həmişə tövsiyə edirdi. Yeniyetmə və gənclərimizin başqa dinlərə qarşı dözümlülük ruhunda tərbiyəsinin vacib məsələ olduğunu vurğulayan Heydər Oliyev eyni zamanda bu işin mürəkkəb və çətin olduğunu da qeyd edirdi: "Məlumdur ki, yüksək tolerantlıq ilk növbədə yüksək mədəniyyətin təzahürüdür. İnsanlarda belə bir mədəniyyətin formalaşdırılmasını uşaqlıq illərindən başlamaq lazımdır. Ölkəmizdə yetişməkdə olan nəslin təhsillənməsində müasir elmi pedaqoji konfranslar daxilində biz ünsiyyət 
mədəniyyətini, dini dözümlük və əməkdaşlıq mədəniyyətini formalaşdırmağa cəhd göstəririk və ümumən desək, buna nail oluruq. Bunu demək çox asandır, lakin gercəkləşdirmək kifayət qədər mürəkkəb bir prosesdir" (Yunusov, A, 2004, s. 91). O, gənclərdə tolerantliq mədəniyyətinin uşaqlıqdan tərbiyə olunmasını diqqətə çəkərək ünsiyyət mədəniyyətinin formalaşdırılması və Azərbaycan gənclərində bu xüsusiyyətlərin tərbiyə edilməsinin vacib şərt olduğunu bizlərə tövsiyə etmişdir. Ulu öndərin siyasətini ləyaqətlə davam etdirən Prezident İlham Oliyevin rəhbərliyi ilə son illərdə Azərbaycan mədəniyyə-tinin inkişafi, milli-mənəvi dəyərlərimizin qorunması, İslam dininə hörmət və ehtiramın güclənməsi, başqa dinlərə qarşı dözümlülüyün daha da möhkəmləndirilməsi sahəsində xeyli iş görülmüşdür. Qeyd edək ki, Prezident İlham Oliyev İslam mədəniyyəti ilə bağlı tarixi-memarlıq abidələrinin, məscid və ziyarətgahların, müqəddəs dini ibadət və inanc yerlərinin təmiri və bərpası ilə bağlı bir çox xüsusi sərəncamlar imzalamışdır.

Azərbaycanda tolerantlığın möhkəm əsasları olduğunu vur-ğulayan Prezident İlham Oliyev respublikamızda yaşayan müxtə-lif din nümayəndələrinin əmin-amanlıq şəraitində rahat yaşadıqla-rını dəfələrlə qeyd etmişdir. Ölkəmizdə müxtəlif dini icmaların dövlət qeydiyyatından keçərək fəaliyyət göstərməsi Azərbaycan-da dini tolerantlığın bariz nümunəsi sayıla bilər.

İslamda tolerantlıq dinin əsas ünsürü kimi qəbul edilir, müqəddəs "Qurani Kərim"də bununla bağlı bütpərəstlərə xitabən buyrulur: "Sizin öz dininiz var, mənim öz dinim" ("Kafirun" surəsi, 6). Bu ayədə insanların sərbəst formada inam növlərinin seçilməsi, demokratik şəkildə vurğulanmışdır və həmin insanlara qarşı xoş münasibət vurğulanır (Д.А.Алимова и др. 2008, s. 91).

Tolerantlıq prinsipləri haqqinda Bəyannamə 16 noyabr 1995-ci il tarixində YUNESKO-ya üzv dövlətlər tərəfindən qəbul edilmişdir. Hər il bu tarix Beynəlxalq Tolerantlıq Günü kimi qeyd edilir, bu problemə aid müxtəlif tədbirlər həyata keçirilir. Bütün insanlar fərqlidir, amma öz dəyər və hüquqlarına görə bərabərdirlər prinsipinə üyğun yazılmış bəyənnamədə dözümlülük, dünyada mədəniyyətlərin, özünüifadənin və insan şəxsiyyətinin təzahürünün müxtəlifliyinin başa düşülməsi, qəbul edilməsi və buna hörmət göstərilməsi vurğulanır. Naxçıvan Muxtar 
Respublikasında tolerantliq prinsipi gənclər üçüniqtisadi və sosial inkişaf imkanı yaradılmasındə öz təzahürünü tapmaqdadır.

\section{SONUC}

Göründüyü kimi, son illər dünyanın dinlərarası və mədəniy-yətlərarası dialoq mərkəzinə çevrilən Azərbaycanda hər bir xalqa və dinə bərabər yanaşma mövcuddur.

İslama didində, tolerantlıq gəncləri milli mənəvi dəyərlər çərçivəsində tərbiyyə etmək, dözümlülük və xeyirxaxlıq nümayiş etdirmək, özündən zəifə eyni cür münasibəti saxlamaq bacarığıdır.

Naxçıvan Muxtar Respublikasında Gənclər siyasətinə əsasən, gənclər üçün bütün şərayit yaradılır, idman komplekstəri tikilir, müxtəlif intellektul oyunlar və yarışmalar keçirilir, düzğün peşə seçimi və milli mənəvi dəyərlərin qorunması sahəsində mütamadi olaraq işlər görünür. $\mathrm{Bu}$ istiqamətində tədbirlər davam etdiriləcəkdir və buna misal olaraq, gənclərdə məşğulluğunun daha da artırılması məqsədi ilə onlayn şəbəkə yaratmaq məqsədəyuğun olardı. Gənclər arasında sahibkarlığın inkişaf etdirilməsi məqsədi ilə seminarlar və təlimlərin keçirilməsi daha aktiv və tolerant insanların yetişdirilməsində böyük töhfə verə bilər.

Təbii ki, ölkəmizdə yaşayan bütün xalqların və dinlərin nümayəndələrinə yaradılan tolerant mühitin təməlində xalqımızın qonaqpərvərliyi, səmimiliyi və bir də bərabər hüquq və humanizmi özündə əks etdirən təkmil qanunvericilik dayanır.

\section{Odəbiyyat}

Ohədov, A. (1991). Azərbaycanda din və dini təsisatlar /Abdulla Ohədov; elmi red. İzzət Rüstəmov.- Bakı: Azərnəşr, 200

Yunusov, A (2004). Azərbaycanda islam /Arif Yunusov; red. Rauf Hüseynov; tərc. M.Mütəllimov.- Bakı: Zaman, 364

Heydər Oliyev və Azərbaycanda din siyasəti: “Gerçək-liklər və perspektivlər" /Azərbaycan Respublikası Dini Qurum-larla İş üzrə Dövlət Komitəsi; H.Orucovun ümumi redaktəsi ilə; tərt. G.İsmayılov; red. S.Nəzərli; rəssam. A.Hüseynov.- Bakı: Obilov, Zeynalov və oğulları, 2007.- $399 \mathrm{~s}$. 
Hüseynov, S. (2012). Azərbaycanda dini tolerantlıq mədəniyyə-ti: tarix və müasirlik /Sakit Hüseynov; elmi red. A.Olizadə.- Bakı: Təknur, [1] s.: portr., cədv., 21 sm., 175

Həsənli, A. (2014). Müasir şəraitdə Azərbaycanda dini-mədəni dəyərlərin inkişaf xüsusiyyətləri: [monoqrafiya] /Anar Həsənli; elmi red. S. Hüseynov; ön söz İ. Rüstəmov.- Bakı: NurArt, 143

Hacıfəxrəddin S. (2017). Naxçıvanın türk-islam mədəniyyəti abidələri, Naxçıvan: Әcəmi, 216

Д.А.Алимова и др. (2008). Исламские ценности Центральной Азии: толерантность и гуманизм: историко-философские и культурные аспекты: [материалы Международной научной конференции] /Французский Ин-т Исследований Центральной Азии; Ин-т истории Акад. Наук Респ. Узбекистан; Международный Ин-т Центральноазиатских Исследований; Ташкентский Исламский Ун-т; Представительство ЮНЕСКО в Узбекистане; ред. кол.Ташкент: [б.и.], 208

Н.И.Киященко и др. (2010). Толерантность в кудьтуре и процесс глобализа-ции /Учреждение Рос. Акад. Наук Ин-т Фидософии РАН, Акад. Гуманитарных Исслед; кол. авт. Москва: Гуманитарий, 486, [1]

“Tolerantlıq örnəyi Azərbaycan": Bakıda Beynalxalq Tolerantlıq Günü münasibətilə konfrans keçirilib//Yeni Azərbaycan.- 2007.- 17 noyabr, 5

Tahirova, N., (2015), Tolerantliq, Bakı, 33

Azərbaycanda dini və milli tolerantlıq //Azadlıq.- 2010.- 20 oktyabr.- 13

Azərbaycan gənclər siyasətin uğurları http://www.sherg.az/2011 $\not 12 / 08 / \mathrm{read}=44284$

\section{Kaynakça Bilgisi / Citation Information}

Cabbarova, S. (2018). Naxçivanda islam mədəniyyəti və gənclərdə tolerantliğin inkişaf etdirilməsi. OPUS - International Journal of Society Researches, 8(Gençlik Araştırmaları Özel Sayısı), 366-374 